Canadian

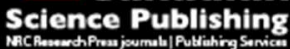

Canadian Journal of Zoology Revue canadienne de zoologie

\title{
Systemic effects of a high saturated fat diet in grizzly bears (Ursus arctos horribilis)
}

\begin{tabular}{|r|l|}
\hline Journal: & Canadian Journal of Zoology \\
\hline Manuscript ID & cjz-2016-0271.R1 \\
\hline Manuscript Type: & Article \\
\hline Date Submitted by the Author: & $12-$ Mar-2017 \\
\hline Complete List of Authors: & $\begin{array}{l}\text { Rivet, Danielle; Washington State University, Department of Biological } \\
\text { Sciences; University of Saskatchewan, Biology } \\
\text { Nelson, O. Lynne; Washington State University, Department of Veterinary } \\
\text { Clinical Sciences } \\
\text { Vella, Chantal; University of Idaho, Department of Movement Sciences } \\
\text { Jansen, Heiko; Washington State University, Department of Integrative } \\
\text { Physiology and Neuroscience } \\
\text { Robbins, C.T.; Department of Natural Resource Sciences }\end{array}$ \\
\hline Keyword: & $\begin{array}{l}\text { Brown Bears, Hibernation, Cardiac Function, Diastolic Function, } \\
\text { Polyunsaturated Fatty Acids, Saturated Fatty Acids, Inflammatory Marker }\end{array}$ \\
\hline &
\end{tabular}

SCHOLARONE $^{\text {IM }}$

Manuscripts 


\title{
Systemic effects of a high saturated fat diet in grizzly bears (Ursus arctos horribilis)
}

\author{
D. R. Rivet, O. L. Nelson, C. A. Vella, H. T. Jansen, C. T. Robbins
}

School of Biological Sciences, Washington State University, Pullman WA 99164, USA, danielle.rivet@wsu.edu

Department of Veterinary Clinical Sciences, Washington State University, Pullman WA 99164,

USA, olnelson@vetmed.wsu.edu

Department of Movement Sciences, University of Idaho, Moscow ID 83844, USA, cvella@uidaho.edu

Integrative Physiology and Neuroscience, Washington State University, Pullman, WA 99164, USA, heiko@vetmed.wsu.edu

School of the Environment and School of Biological Sciences, Washington State University, Pullman WA 99164, USA, ctrobbins@wsu.edu

\section{Author Correspondence:}

Danielle Rivet

W. P. Thompson Biology Building

112 Science Place

University of Saskatchewan

Saskatoon, SK S7N 5E2

(306)220-3028

danielle.rivet@usask.ca 


\begin{abstract}
Food sources for North America's brown bear (Ursus arctos horribilis Ord, 1815) population have changed as habitats have fragmented, altering available resources and putting bears in contact with unnatural foods. Bears have evolved mechanisms to tolerate obesity, and do not develop adverse health consequences despite storing massive amounts of body fat. Captive adult grizzly bears were used to determine the effects of dietary fat on health. Group 1 was fed a diet high in polyunsaturated fatty acids (PUFA) wherein 9.5\% of available calories came from saturated fatty acids (SFA). Group 2 was fed a diet wherein $28.8 \%$ of calories came from SFA. Plasma fatty acids, serum lipid profiles, insulin, inflammatory markers, systolic and diastolic blood pressure, and cardiac function parameters were measured. Serum lipids, SFA, and insulin did not differ between the two groups, although omega-3 fatty acids differed. Bears eating the SFA diet had significantly higher circulating adiponectin, interleukin 7 and 15, and tumor necrosis factor-alpha. Mild, asymptomatic systolic and diastolic dysfunction were detected by strain echocardiography in the SFA group. The SFA diet group exhibited higher diastolic arterial pressures. Even though mild metabolic derangements were observed, grizzly bears were remarkably resistant to metabolic effects of diets high in SFA.
\end{abstract}

Keywords: brown bears, Ursus arctos, hibernation, cardiac function, diastolic function, polyunsaturated fatty acids (PUFA), saturated fatty acids (SFA), inflammatory marker 


\section{Introduction}

The grizzly bear (Ursus arctos horribilis Ord, 1815) is a North American subspecies of the brown bear that inhabits Alaska, much of western Canada, and portions of the northwestern United States. While brown bears are normally thought of as apex predators utilizing meat as a significant part of their diet, many brown bears in North America are more commonly omnivorous in that they feed not only on fish, small mammals, and ungulates, but also consume large quantities of berries, tubers, grasses, forbs, and nuts (Welch et al. 1997; Felicetti et al. 2003; Fortin et al. 2013). In preparation for hibernation, bears feed voraciously in the fall (e.g., hyperphagia) to accumulate fat that will be used as the energy source for hibernation (Stenvinkel et al. 2012). Furthermore, brown bears prefer diets that are fat laden. Grizzly bears given ad libitum access to lipids, carbohydrates, and protein chose a fall diet in which lipids provided 73\% $\pm 3 \%$ of metabolizable energy (Erlenbach et al. 2014). Grizzly bears often attain body fat levels of $30-40 \%$ in autumn that are considered 'obese to morbidly obese' by human standards (Grundy 2004; AACE/ACE Obesity Task Force 1998).

Food sources for North America's brown bears have changed as habitats have shifted and fragmented in the last century. Diets deemed healthy for humans are typically high in monounsaturated fats (MUFA), polyunsaturated fatty acids (PUFA), plant proteins, whole grains, fish, fruits, and have lower quantities of red meats, are thought to be generally more similar to bear's natural diet. However historically, it is likely that bears living in interior regions of the United States that had access to large ungulates consumed a larger proportion of saturated fatty acids (SFA) compared to those feeding largely on PUFA-rich plant- or marine-based diets (Jacoby et al. 1999). As humans have increasingly occupied bear habitat, bear diets have been altered. For example, bears feeding on human foods left behind by park visitors in dumpsters or 
in camps is not unusual, as bears in Yellowstone consumed garbage from dump sites for more than 100 years (Craighead et al. 1995; Beckmann and Berger 2003). In addition, brown bear populations have lost access to PUFA-rich anadromous salmon or may have greater access to non-native foods such as livestock carcasses that are generally fatter than wild ungulates. These food resource changes may introduce relatively higher amounts of SFA into brown bear diets. Dietary patterns of fatty acid consumption, particularly the ratio of SFA and PUFA, are thought to be associated with the development of many diseases in humans including but not limited to obesity (Phillips et al. 2012), cardiovascular disease (Siri-Tarino et al. 2010), coronary heart disease (Jakobsen et al. 2009; Siri-Tarino et al. 2010), Type 2 diabetes (Tur et al. 2012), and metabolic syndrome (Tur et al. 2012). Although evidence on the effects of consuming a diet high in SFA on cardiovascular health is unclear, the research suggest that replacing SFA with PUFA, particularly omega-3 PUFA has beneficial effects on cardiovascular morbidity and mortality (Jakobsen et al. 2009; de Lorgeril and Salen 2012; Siri-Tarino et al. 2010). Many of the conditions associated with a less than optimal dietary fat pattern are mediated by altered lipid parameters, insulin resistance, and systemic inflammation and are thus relatively easy to recognize in serum biochemistry profiles (Ärnlöv et al. 2005; Roberts et al. 2009). Obesity alone has also been shown to be an independent risk factor for heart disease in humans, even after accounting for comorbid conditions such as Type 2 diabetes and coronary artery disease (Roberts et al. 2009; Orhan et al. 2010). Subclinical cardiac diastolic dysfunction appears to be a common initial consequence of obesity and may be overlooked early in the clinical evaluation (Millen et al. 2014; Sanchez et al. 2014). Such findings highlight the potential for lipid-induced heart dysfunction prior to overt clinical signs. 
Because of the alterations in habitat and food sources, we wanted to know if the type of dietary fat consumed would affect the overall health and hibernation patterns of brown bears. For example, several species of hibernating rodents experience longer hibernation periods, reduced arousal activity and lower body temperatures after consuming diets high in PUFA compared to diets high in SFA (Geiser and Kenagy 1987; Geiser et al. 1994; Harlow and Frank 2001; Frank et al. 2008). This is thought to be due to the preferential incorporation of PUFAs into the animals' cell membranes and storage lipids where they are presumably more metabolizable at colder body temperatures than SFAs (Geiser and Kenagy 1987; Frank et al. 2008). In addition to hibernation patterns, we wanted to know whether brown bears would show evidence of harmful health conditions that humans tend to develop while eating diets high in SFA and more refined foods.

For this study, we fed 2 distinct diets to a group of 4 captive brown (grizzly) bears over a 2-year period in a cross-over design. We chose diets to maximize the difference between the SFA and PUFA to create the most dramatic challenge to determine whether bears would be affected by these dietary fat parameters. We assessed health effects of the diets by analyzing in vivo cardiovascular parameters, serum chemistries and inflammatory markers, lipid profiles, and hibernation patterns by physical activity monitor. We hypothesized that a diet high in PUFAs, particularly omega-3, and complex carbohydrates would be healthier for the bears than a diet high in SFAs and refined sugars. We further hypothesized that even though the PUFA and complex carbohydrate diet would be healthier for the bears, the bears would be more resistant than humans to major metabolic derangement when consuming diets high in SFAs because of their evolutionary selection for obesity. Likewise, we hypothesized that diets high in SFA would not affect the activity patterns of hibernating brown bears as occurs in rodents because of the higher hibernating body temperature in bears. 


\section{Methods and Materials}

\section{Animals}

Four adult female grizzly bears (aged 7 to 11 years) were studied for 2 full active and hibernation periods (summer of 2012 through the winter of 2014). All animals were housed at the Washington State University Bear Research, Education, and Conservation Center, and maintained in compliance with ASM guidelines (Sikes et al. 2011) and the Bear Care and Colony Health Standard Operating Procedures approved by the Washington State University Institutional Animal Care and Use Committee (IACUC) (ASAF \#3054 and 4476). Animals had routine access to a 0.56 -ha enclosure for physical activity. Because of confounding effects of anesthesia on in vivo assessment of certain parameters (Nelson and Robbins 2010), the bears were trained for voluntary echocardiography, blood pressure measurement and blood collection. Therefore, all 4 bears were fully conscious for this study and participated in a comfortable handling routine that allowed for data collection.

Feeding for the study began in May of each year and continued through October, when all feeding was ceased in preparation for hibernation. We strived to maintain similar body composition and overall condition between years to avoid the potential confounding effect of one diet group becoming significantly fatter than the other. As hibernation approached, food was gradually reduced until completely withdrawn at the end of October. Water was provided ad libitum year round. Bears hibernated in unheated, indoor dens ( $3 \mathrm{~m} \times 3 \mathrm{~m} \times 2.5 \mathrm{~m})$ with continuous access to outdoor runs $(3 \mathrm{~m} \times 3 \mathrm{~m} \times 5 \mathrm{~m})$ that enabled the bears to experience regular light and temperature fluctuations throughout hibernation. Dens were monitored with surveillance cameras (OpenEye Digital Video Security Solutions, Spokane, WA), and bear movement was quantified 
throughout hibernation with Actical ${ }^{\mathrm{TM}}$ physical activity monitors (Minimitter, Bend, OR) attached to the skin with epoxy at the neck and shoulder area.

Diet

Two distinct diets were established and fed to the bears for the duration of the active seasons of the study. The diets were a high PUFA, complex carbohydrate diet versus a high SFA, refined carbohydrate diet which were formulated based on recommendations for humans according to the USDA Dietary Guidelines for Americans (2010). In order to be assured of a challenge on the bears' metabolic systems, the recommended SFA allowance for humans (i.e., $<$ $10 \%$ of caloric intake coming from saturated fats) was multiplied 2 to 3 times in formulating the high SFA bear diet. Thus, a diet high in SFAs was designed with the goal of providing 20-30\% of the total calories as SFA, whereas the PUFA diet provided $\leq 10 \%$ of the calories from SFAs (Table 1).

Chinook salmon (Oncorhynchus tshawytscha (Walbaum, 1792)), salmon oil and cut oats were components of the PUFA diet that provided unsaturated fats and complex carbohydrates. Specifically, Chinook salmon and salmon oil are high in omega-3 and low in omega-6 PUFA. The steel cut oats are high in complex carbohydrates and fiber and low in simple carbohydrates. Together these ingredients allowed for an $18.3 \%$ higher level of polyunsaturated fats and a higher ratio of PUFA to SFA in the PUFA diet compared to the SFA diet. Beef fat, cheddar cheese and high fructose corn syrup (HFCS) were components of the SFA diet, which provided saturated fats and added sugars (Table 1). HFCS was included in the SFA diet in place of oats to maximize the bears' metabolic challenge because of its association with obesity and metabolic disturbance in humans (Brown et al. 2008). Because human diets often contain HFCS (Brown et al. 2008), we added HFCS to the SFA diet as bears consuming garbage are likely to consume 
HFCS, which may affect their health. Both diets included a consistent quantity of apples and commercial chow to supply a balanced vitamin and mineral source and an equal amount of dietary fiber from these base foods. We strived to maintain a similar amount of gross energy per diet (Table 1), so this resulted in the proportion of the diet being supplied by commercial chow and apples being slightly different.

The diets were freeze dried, ground, and nutritionally evaluated for total fat, trans fat, gross energy, crude protein, and fatty acids (Table 2) by a commercial laboratory (Agricultural Experiment Station Chemical Laboratories, University of Missouri, Columbia, MO, USA). Twenty-seven fatty acids were analyzed. Each type of food was weighed and recorded before daily feedings. Two bears received the PUFA diet and 2 bears received the SFA diet for the active season of 2012. The bears that were fed the SFA diet in 2012 were switched to the PUFA diet in 2013, and vice versa. Thus, all 4 bears received both diets, and differences in winter weather that might affect hibernation were controlled for between years when examining the effect of diet on hibernation.

\section{Body Composition}

Bears were weighed 2 to 4 times/month depending on the need to control mass gain. Body composition was determined monthly by water dilution (Farley and Robbins 1994). A baseline blood sample was taken from a hind limb prior to injection of $8 \mathrm{~mL}$ of $99.8 \%$ deuterium oxide, which was followed by a flush with sterile saline solution. A 1-hour post-deuterium oxide injection blood sample was also taken. While previous studies using anesthetized bears found that 2 hours were required for equilibration of the deuterium oxide (Farley and Robbins 1994), our preliminary studies indicated that 1 hour was sufficient for complete equilibration in the unanesthetized bear. A commercial lab (Metabolic Solutions, Inc., Nashua, NH) analyzed pre- 
and post-injection samples by cavity ring-down spectroscopy. This method has been validated against isotope ratio mass spectrometry (Crosson 2008; Thorsen et al. 2011). From these analyses, $\delta$ deuterium values for pre- and post-injection samples $\left(\delta_{\text {pre }}\right.$ and $\left.\delta_{\text {post }}\right)$ were determined, and total body water was calculated from the dilution of the isotope using the equation:

$$
\mathrm{TBW}(\text { moles })=\frac{\mathrm{WA}}{18.02 \mathrm{a}} \times \frac{\left(\delta_{\text {dose }}-\delta_{\text {tap }}\right)}{\left(\delta_{\text {post }}-\delta_{\text {pre }}\right)}
$$

where $W$ is the amount of tap water in grams used to dilute the dose, $A$ is the amount of deuterium oxide dose in grams administered to the bear, and $a$ is the amount of dose in grams diluted for analysis. Because deuterium can bind to some acidic amino acids, the total body water measurement was divided by 1.04 to correct for the non-exchange of deuterium (Farley and Robbins 1994; Metabolic Solutions 2014). Total body fat was then determined based on the corrected total body water.

Serum Chemistries, Plasma Fatty Acids, and Inflammatory Markers

Blood samples were collected in the spring (April), approximately 6 weeks after emergence from hibernation, and in the fall (September) approximately 6 weeks prior to hibernation at a time when the bears had obtained the greatest adiposity. Samples were collected into serum and EDTA tubes. Serum tubes were centrifuged at $4^{\circ} \mathrm{C}$ and $1750 \mathrm{rpm}$ for 20 minutes, and serum and plasma were transferred by pipette into separate o-ring cryovials for storage. Serum and plasma samples were kept at $-80^{\circ} \mathrm{C}$ until analyzed. The Clinical Pathology Laboratory at Washington State University ran a routine serum chemistry panel within 90 minutes of collection.

Frozen serum was submitted in batch to Amgen Clinical Pathology Laboratory (Thousand Oaks, CA, USA) for lipid profiles consisting of triglycerides, total cholesterol, highdensity lipoprotein cholesterol (HDL), low-density lipoprotein cholesterol (LDL), non-esterified 
fatty acids (NEFA) and insulin concentration. Serum was analyzed for adiponectin with a commercial ELISA mouse-rat assay kit (B-Bridge International, Inc. San Jose, CA, USA.) previously validated in bears (Lusby et al. 2008) and inflammatory cytokines with a canine cytokine multiplex assay (EMD Millipore Milliplex ${ }^{\circledR}$ Billerica, MA, USA.) using a Luminex based assay validated by the manufacturer. With the exception of CRP, most of these markers have significant homology among species, but validation studies using bears have not been performed with Luminex based assays. Adiponectin and cytokine serum concentrations were determined via a standard regression curve per manufacturers' instructions. Inflammatory markers examined included: granulocyte-macrophage colony stimulating factor (GM-CSF), interleukin (IL)-2, 6, 7, 8, 10, 15, 18, tumor necrosis factor-alpha (TNF- $\alpha$ ), interferon-gamma (INF-gamma), C-reactive protein (CRP), monocyte chemoattractant protein-1 (MCP-1), interferon gamma-induced protein-10 (IP-10), and keratinocyte-derived chemokine (KC)-like.

Plasma was analyzed for fatty acid content via capillary gas chromatography/mass spectrometry by a commercial laboratory (Metametrix Clinical Laboratory, Duluth, GA, USA), and a complete profile of fatty acids was derived for each bear. Concentrations of omega-3, omega-6, and omega-9 polyunsaturated fatty acids, monounsaturated fatty acids, saturated fatty acids, odd chain fatty acids and trans isomers from hydrogenated oils were measured. The specific fatty acids measured were: alpha linolenic, eicosapentaenoic, docosapentaenoic, docosahexaenoic, linoleic, gamma linoleic, eicosadienoic, dihomogamma linolenic, arachidonic, docosadienoic, docosatetraenoic, mead, myristoleic, palmitoleic, vaccenic, oleic 11-eicosenoic, nervonic, capric, lauric, myristic, palmitic, stearic, arachidic, behenic, lignoceric, hexacosanoic, pentadecanoic, heptadecanoic, nonadecanoic, heneicosanoic, tricosanoic, palmitelaidic, and total $\mathrm{C}: 18$ trans fatty acids. 


\section{Echocardiography}

Trained bears underwent a complete transthoracic echocardiographic examination that included 2-dimensional, M-mode, spectral and color-flow Doppler evaluations. Echocardiography was performed by the same person (OLN) using commercially available equipment (My Lab 30, Biosound Esaote, Indianapolis, IN, USA). The bears were imaged in sternal recumbency with forelegs positioned cranially to optimize the parasternal thoracic windows. Standard imaging planes and global function calculations have been previously described for cats and dogs (Thomas et al.1993). All measures were performed in accordance with the American Society of Echocardiography for cardiac volume and functional calculations (Schiller et al. 1989; Kuecherer et al. 1991; Ommen et al. 2000; Rajagopalan et al. 2001). Strain echocardiography was also performed to assess regional (vs global) myocardial diastolic motion, as previously described in dogs (Chetboul et al. 2006; Tidholm et al. 2009).

These examinations were performed in the spring (late April) post hibernation and in the fall (mid-September) prior to any changes in heart function associated with hibernation (Nelson and Robbins 2010). Video images were recorded using a commercially digital echocardiography software program and data were analyzed off-line using a workstation (Biosound Esaote Indianapolis, IN, USA). Volume parameters were normalized to body weight in order to account for disparities in body size between bears, as is customary for large mammals (Schiller et al. 1989). A total of 19 standard echocardiographic parameters assessing global cardiac chamber function (see Supplemental Information S1) and 17 strain echocardiographic parameters assessing regional myocardial motion (Table 3 ) were collected during the evaluations, with emphasis on determining differences in diastolic function of the heart.

\section{Blood Pressure}


Systolic and diastolic arterial blood pressure was measured from the bears' left dorsal metatarsal artery using an inflatable cuff and the Doppler technique (Parks Medical Electronics, Inc, Aloha OR, USA) in the pre and post hibernating period. The cuff size was determined by taking $40 \%$ of the circumference of the limb just proximal to the hock (McLeish 1977; Haskins 1992). The same person (DR) performed the test for all bears. Three to 4 measurements were recorded and averaged to provide a single value for that time period. The indirect Doppler technique was validated in 4 bears prior to use in this study. Four bears, two adult females (age 12 and 15 years) and two adult males (age 12 years) were anesthetized to compare direct and indirect blood pressure measures. These bears were given an intramuscular injection using a combination of a reversible $\alpha 2$ agonist $(6.04 \mu \mathrm{g} / \mathrm{kg}$ dexmedetomidine) and a nonreversible $\mathrm{N}$ methyl-D-aspartate (NMDA) agonist with tranquilizer $(1.23 \mathrm{mg} / \mathrm{kg}$ tiletamine and $1.23 \mathrm{mg} / \mathrm{kg}$ zolazepam, Fort Dodge Animal Health, Fort Dodge, IA) (Teisberg et al. 2014). The femoral artery was immediately catheterized for a direct arterial blood pressure measure (BeneView T5, Mindray Medical USA Corp, Redmond WA, USA). Simultaneously, blood pressure was measured using the indirect Doppler technique on the opposite rear limb. Blood pressures determined by direct artery catheterization did not differ from the indirect Doppler technique indicating that indirect measures are accurate [systolic: direct $253 \pm 24$, indirect $260 \pm 25(P=$ $0.73)$; diastolic: direct $158 \pm 8$, indirect $160 \pm 10(P=0.68)]$.

\section{Activity Monitors}

Bear activity during the active season and hibernation was monitored with Actical ${ }^{\mathrm{TM}}$ physical activity monitors (Phillips Respironics, Bend, OR, USA) encased in aluminum protective cases and glued to the skin with 2-part epoxy at the shoulder (Ware et al. 2012). Application and removal of the acticals was performed on bears trained to remain still for a food 
reward. Incidence of movement and movement velocity data were collected in 1-minute epochs via an omnidirectional accelerometer sampling at $32 \mathrm{~Hz}$ and converted to counts (resolution 100 counts or $0.02 \mathrm{G}$ at $1 \mathrm{G}$ peak). Activity monitors were removed after the bears emerged from hibernation in the spring, and the data were downloaded into Actical 2.12 software (Phillips Respironics, Bend, OR, USA). The data were then exported and analyzed for average daily total activity (counts/day) during the active season (March through October), during the deepest part of hibernation (December 15 through January 15), and throughout the total hibernation duration (November through February).

\section{Statistical Analysis}

All analyses in this study were performed using IBM SPSS version 22.0. Assumptions for analyses were all conducted independently and met. Each variable was screened for missing data. Each quantitative variable had no missing values. This was largely due to the low sample size. Paired-samples t-tests have been shown to be appropriate with extremely small sample size $(\mathrm{N} \leq 5)$, specifically when the within-pair Pearson coefficient is high (de Winter 2013). The Shapiro-Wilk statistic showed a non-significant departure from normality for all variables. Examination of Q-Q plots for all variables did not indicate serious departures from normality. A paired-samples t-test was used to determine whether there was a statistically significant mean difference between the test groups. No outliers were detected defined as more than 1.5 boxlengths from the edge of the box in a boxplot. Further investigation of the scores did not reveal the need to remove values; thus, they were kept in the analysis. A $P$ value of $\leq 0.05$ was considered significant. All results are presented as means $\pm \mathrm{SD}$.

\section{Results}


Diet

Approximately $28.8 \%$ and $9.5 \%$ of the total calories came from saturated fatty acids in the SFA and PUFA diets, respectively (Table 1). The relative concentration of SFAs fed was approximately twice as high in the SFA diet as in the PUFA diet. Similarly, the relative concentration of PUFAs fed in the PUFA diet was approximately three times higher compared to the SFA diet (Table 2).

Body CompositionFood intake and body mass increased as the bears prepared for hibernation (Fig. 1). No significant difference in percent body fat was found between the 2 diet groups $(P=$ 0.86). Percent body fat in May and September for the SFA group was $23 \% \pm 5 \%$ and $34 \% \pm 2 \%$, while percent body fat for the PUFA group was $22 \% \pm 5 \%$ and $35 \% \pm 7 \%$.Blood Chemistries, and Inflammatory Markers

Serum biochemistries and lipids, including cholesterol, HDL, LDL, SFA, and NEFA, did not differ between the two diet groups in the spring or fall. However, total cholesterol, HDL, LDL, and NEFA in bears were elevated as compared to human standards (Table 2). Bears eating the PUFA diet had significantly higher levels of omega-3 fatty acids in the fall than did those on the SFA diet. Bears eating the SFA diet had higher levels of some omega-6 fatty acids, including gamma linoleic and dihomogamma linolenic, as well as the omega-9 fatty acids docosatetraenoic and mead acid than did bears consuming the PUFA diet (Table 2).

Serum adiponectin levels were significantly higher $(P<0.001)$ in bears consuming the SFA diet $(17.2 \pm 2.9 \mu \mathrm{g} / \mathrm{mL})$ than in bears consuming the PUFA diet $(9.5 \pm 2.5 \mu \mathrm{g} / \mathrm{mL})$. Of the 13 inflammatory cytokines analyzed, only 3 were significantly different between diet groups. TNF- $\alpha$ was higher in bears eating the SFA diet $(11.7 \pm 1.8 \mathrm{pg} / \mathrm{mL})$ than those consuming the PUFA diet $(9.7 \pm 1.8 \mathrm{pg} / \mathrm{mL})(P<0.01)$. IL-7 was higher in bears eating the SFA diet $(56.1 \pm 40$ 
pg/mL); PUFA diet $(39.8 \pm 33.1 \mathrm{pg} / \mathrm{mL})(P=0.03)$. IL-15 was higher in bears eating the SFA $\operatorname{diet}(60.7 \pm 29 \mathrm{pg} / \mathrm{mL}) ;$ PUFA $\operatorname{diet}(49 \pm 29.1 \mathrm{pg} / \mathrm{mL})(P=0.02)($ Fig. 2$)$.

Heart and Circulatory Function

There were no differences detected in standard echocardiography parameters between the 2 diet groups in the spring or fall (see Supplemental Information S1). However, myocardial strain imaging detected significant differences in regional left ventricular wall motion between the 2 diet groups in the fall (Table 3). Bears in the SFA group had slower ventricular wall motion in systole (longitudinal direction of wall contraction) and in early diastole (transverse velocity of wall relaxation, Fig. 3). Bears in the SFA group had higher atrial contraction velocities in late diastole (both longitudinal and transverse directions) indicating decreased ventricular compliance during atrial contraction. These parameters indicate left ventricular diastolic impairment in the SFA group. Blood pressure did not differ between to 2 groups of bears in the spring. Bears eating the SFA diet exhibited higher diastolic arterial pressures than the PUFA group in the fall, but systolic arterial blood pressures did not differ (Table 3).

Activity

While average total daily activity was significantly different across seasons $(P<0.01)$ in that bears displayed more daily activity during the active season than the hibernation season, there were no differences in activity between the diet groups during the deeper part of hibernation $(P=0.48)$ or for total hibernation period $(P=0.33)$ (Fig. 4).

\section{Discussion}

Although bears were obese in the fall by human standards (Gallagher et al. 2000; Pescatello et al. 2014), there were fewer metabolic derangements compared to that expected for 
obese humans consuming similar diets (Fung et al. 2001; Brown et al. 2008; Heidemann et al. 2008; Fung et al. 2009; Estruch et al. 2013). One consideration for the observed difference between species is that metabolic dysfunction is something that develops over time in humans who remain obese. Bears do not remain obese throughout the year, but gain and then lose weight seasonally. Moreover, insulin resistance and hyperinsulinemia, two hallmarks of metabolic syndrome, develop only during hibernation in bears (Rigano et al. 2016) and only at specific times of the year. Together these results suggest that bears have experienced extensive evolutionary selection to accumulate large amounts of fat to survive hibernation while remaining healthy and reproductively active (LeBlanc et al. 2001; Viscarra and Ortiz 2012; Robbins et al. 2012; Lopez-Alfaro et al. 2013). For example, females with greater adiposity produce larger cubs with a better chance of survival compared to leaner bears (McLellan 2011; Robbins et al. 2012), and larger bodied males do most of the breeding (Dahle et al. 2006; Kovach and Powell 2003). This has resulted in bears with dramatically increased appetites in the fall, and a preference for high-fat diets (Robbins et al. 2012; Erlenbach et al. 2014). As such, obesity as defined by human standards may be healthy or even necessary for this species to thrive and reproduce.

The significant differences in serum fatty acid profiles in response to the 2 diets suggested that the diets were sufficient to induce biochemical changes in the circulation by the fall. The degree of alteration observed in plasma fatty acids due to the diets would have health consequences in humans. For example, omega-3 fatty acids (e.g., docosapentaenoic, docosahexaenoic, and eicosapentaenoic acids) are known to have many health benefits, including protecting against inflammation, coronary artery disease, and ischemic stroke (Esposito et al. 2004; Ruxton 2004; Chen et al. 2011; Tur et al. 2012). The omega-6 fatty acids (e.g., gamma 
linoleic and dihomogamma linolenic acids) that were elevated in bears consuming the SFA diet are associated with increased inflammation, coronary artery disease, and ischemic stroke and often inhibit the production of omega-3 fatty acids in humans (Guebre-Egziabher et al. 2008). Furthermore, high levels of docosatetraenoic acid, which was twice as high in the serum of the SFA bears, are correlated with obesity and implicated in insulin resistance in humans (Kusunoki et al. 2007). Interestingly, levels of serum monounsaturated and saturated fatty acids did not differ significantly between the 2 diet groups. In hibernators, fatty acids provide the major source of energy and despite the high rate of hepatic $\beta$-oxidation, long-chain polyunsaturated fatty acids are selectively conserved (Xia et al. 1993). Evidence from other studies on black bears (Ursus americanus Pallus, 1780) and elephant seals (Mirounga angustirostris Gill, 1866) suggest that saturated fatty acids are preferentially mobilized and metabolized for mitochondrial oxidation, while PUFA are spared and likely conserved for other purposes (LeBlanc et al. 2001; Viscarra and Ortiz 2013). Therefore, bears may be more resistant to the effects of high SFA diets that would otherwise be detrimental to humans.

Though differences in consumption of PUFA and SFA in hibernating rodents have been shown to affect torpor bout duration and arousal activity (Geiser et al. 1994; Harlow and Frank 2001; Florant et al. 1993), no significant differences were noted in hibernation activity levels between the diet groups in bears. Metabolism of fatty acids may be less problematic for bears as they hibernate at a warmer body temperature than do rodents. While the difference in hibernation activity by bears on the PUFA diet appeared to show a similar trend to that observed in rodents (i.e., decreased activity in hibernation), the required sample size of bears to detect a statistical difference based on the observed variation suggests our current sample size would represent a limitation to detect a significant difference. 
Serum adiponectin, was highest in bears consuming the SFA diet. Adiponectin is a metabolically active cytokine exclusively secreted from adipose tissue that modulates several metabolic processes, including insulin resistance and fatty acid oxidation, preventing fatty liver disease (You et al. 2005), and preventing arterial inflammation and atherosclerosis (Libby et al. 2010; Arinell et al. 2012). In humans, adiponectin is inversely associated with obesity, Type 2 diabetes, atherosclerosis, and other derangements linked with metabolic syndrome (FernándezReal et al. 2005; You et al. 2005; Murakami et al. 2013; Santos et al. 2013). Therefore, lower adiponectin levels in the blood of humans are often coupled with higher percent body fat and increased intake of saturated fatty acids (Fernández-Real et al. 2005; Reis et al. 2010). Unlike humans, bears displayed a positive correlation between percent body fat, high SFA diet and circulating adiponectin levels. Some of these differences between bears and humans in adiponectin secretion may occur because bears accumulate virtually all of their fat in subcutaneous deposits, whereas humans tend to accumulate visceral fat, which is associated with decreases in adiponectin levels and negative health consequences (Asayama et al. 2003; Lenchik et al. 2003; Fontana et al. 2007). In addition, seasonal changes in adiponectin are expected for hibernating mammals. For example, adiponectin is lower in winter as these animals switch from lipogenesis during the active season to lipolysis and insulin resistance during hibernation (Florant et al. 2004; McCain et al. 2013). As such adiponectin may serve a different physiologic process in hibernators than it does in humans, meaning high or low serum levels in bears do not imply the same pathologic processes.

Of the 13 inflammatory cytokines tested, only TNF- $\alpha$, IL7 and IL 15 showed significant differences between diet groups, suggesting little inflammation in bears regardless of adiposity or diet, though many inflammatory markers were elevated compared to human standards (Figure 
2). All three of these cytokines are known to have prominent biological effects on metabolic and cardiac health in humans and other mammals (Pagani et al. 1992, Lang et al. 2001; Alam et al. 2004; Saidijam et al. 2014).

For example, TNF- $\alpha$ is a proinflammatory cytokine thought to play a role in the pathogenesis of heart failure as intravenous infusion of TNF- $\alpha$ in animal models produces immediate negative effects on myocardial contraction and promotes chamber dilation (Oral et al. 1995; Lang et al. 2001). The suspected cell signaling pathways responsible for these effects are believed to be production of nitric oxide (NO), secondary to TNF- $\alpha$ induced expression of the inducible form of nitric oxide synthase (iNOS) (Mann and Young 1994; Oral et al. 1995). Continuous TNF- $\alpha$ infusion in dogs alters the diastolic elastic properties of the ventricle by altering expression of extracellular matrix proteins and their regulatory proteins (Pagani et al. 1992), while other studies have documented impairment of cardiac muscle mRNA protein translation by TNF- $\alpha$ infusion (Mauviel et al.1991; Lang et al. 2001). Thus, it is possible that increased TNF- $\alpha$ in the SFA group is related to the cardiovascular differences noted in these bears. However, even though the difference in TNF- $\alpha$ is significant, the overall levels are relatively low compared to humans.

Interleukins also play a key role in inflammation and modulate metabolic functions. IL7, known as B cell precursor growth factor, has a key role in lymphocyte homeostasis, especially in basal metabolism of glucose. It maintains high glucose uptake and expression of GLUT1 which results in adequate glycolytic flux (Saidijam et al. 2014). IL 15 is a more recently studied cytokine which appears to have functions in regulating adipose tissue deposition (Quinn and Anderson, 2011). Both cytokines have been implicated in the mechanism underlying metabolic syndrome and cardiovascular dysfunction. In addition, cell adhesion molecules, growth factors 
and proinflammatory cytokines have been identified in excessive concentrations in the setting of acute coronary syndrome associated with obesity. These factors lead to vascular endothelial dysfunction, plaque vulnerability and thrombogenicity (Alam et al. 2004).

Clinical studies support that indices of adiposity and pro-inflammatory cytokine levels in obesity are 1) correlated with dyssynchrony in ventricular contraction and relaxation and 2) are an independent predictor of cardiac mortality (Marfella et al. 2004). While bears did not exhibit clinical symptoms of cardiovascular disease during this study, we did note significant decreases in ventricular contraction and primarily relaxation rates in bears eating the SFA diet as well as higher diastolic blood pressures in this group. Subclinical cardiac diastolic dysfunction is a common initial consequence of human obesity and may be overlooked early in the clinical evaluation if exercise testing is not performed. Over time, functional changes may deteriorate into clinical disease, although the timeframe for progression is variable. It is unknown whether the cardiovascular differences seen in these bears could be the result of inflammatory cytokines or tissue/endothelial oxidative changes as described for other species eating high SFA diets (Sun et al. 2012). The mechanisms behind these observations warrant further investigation.

Our findings suggest a less dramatic degree of metabolic disturbance and cardiac dysfunction associated with consumption of foods containing high levels of saturated fats and HFCS than compared to humans. While the SFA diet in our study appears less healthy for bears, the animals remained relatively resistant to developing metabolic derangements or severe clinical disease in a timeframe when such anomalies would be expected to occur in humans. Though bears in the SFA group were asymptomatic, it is important to note that our study is small and occurred over a single feeding season for each group. Wild bears relying heavily on human 
refuse or bears residing in captive facilities could potentially be more negatively affected over a longer term by similar diets.

\section{Acknowledgments}

Funding was provided by the Interagency Grizzly Bear Committee, United States Fish and Wildlife Service, Amgen, Inc., Washington State University College of Veterinary Medicine, the Raili Korkka Brown Bear Endowment, Bear Research and Conservation Endowment, and Nutritional Ecology Endowment at Washington State University. Thanks are extended to Joy Erlenbach, Heidi Keen, Dara Reinbold, Jamie Gehring, and Kimberly Rigano for collaboration in collecting data, excellent technical assistance, and management of bear care.

\section{Ethical Approval}

All applicable international, national, and/or institutional guidelines for the care and use of animals were followed. All procedures performed in studies involving animals were in accordance with the ethical standards of the institution or practice at which the studies were conducted.

\section{References}

Alam, S.E., Nasser, S.S., Fernainy, K.E., Habib, A.A., and Badr, K.F. 2004. Cytokine imbalance in acute coronary syndrome. Curr. Opin. Pharmacol. 4(2):166-170. doi: 10.1016/j.coph.2003.10.011.

Arinell, K., Sahdo, B., Evans, A.L., Arnemo, J.M., Baandrup, U., and Fröbert, O. 2012. Brown bears (Ursus arctos) seem resistant to atherosclerosis despite heavily elevated plasma 
lipids during hibernation and active state. Clin. Transl. Sci. 5(3):269-272. doi: 10.1111/j.1752-8062.2011.00370.x.

AACE/ACE Obesity Task Force. 1998. AACE/ACE position statement on the prevention, diagnosis, and treatment of obesity. Endocr. Pract. 4(5):297-350. Available from: $\underline{\text { http://citeseerx.ist.psu.edu/viewdoc/download?doi=10.1.1.177.3176\&rep=rep } 1 \& \text { type=pdf }}$ [accessed on 11 April 2014].

Ärnlöv, J., Lind, L., Sundström, J., Andrén, B., Vessby, B., and Lithell, H. 2005. Insulin resistance, dietary fat intake and blood pressure predictleft ventricular diastolic function 20 years later. Nutr. Metab. Cardiovasc. Dis. 15(4):242-249. doi: 10.1016/j.numecd.2004.10.002.

Asayama, K., Hayashibe, H., Dobashi, K., Uchida, N., and Nakane, T. 2003. Decrease in serum adiponectin level due to obesity and visceral fat accumulation in children. Obes. Res. 11(9):1072-1079. doi: 10.1038/oby.2003.147.

Beckman, J.P., and Berger, J. 2003. Rapid ecological and behavioral changes in carnivores: the responses of black bears (Ursus americanus) to altered food. J. Zool. (Lond.) 261(2):207212. doi: $10.1017 / \mathrm{s} 0952836903004126$.

Brown, C.M., Dulloo, A.G., and Montani, J.P. 2008. Sugary drinks in the pathogenesis of obesity and cardiovascular diseases. Int. J. Obes. 32:S28-S34. doi: 10.1038/ijo.2008.204.

Chauhan, V.P.S., Tsiouris, J.A., Chauhan, A., Sheikh, A.M., Brown, W.T., and Vaughan, M. 2002. Increased oxidative stress and decreased activities of $\mathrm{Ca}^{2+} / \mathrm{Mg}^{2+}-\mathrm{ATPase}$ and $\mathrm{Na}^{+} / \mathrm{K}^{+}$-ATPase in the red blood cells of the hibernating black bear. Life Sci. 71(2):153161. doi: 10.1016/s0024-3205(02)01619-3. 
Chen, J.G., Shearer, G.C., Chen, Q., Healy, C.L., Beyer, A.J., Nareddy, V.B., Gerdes, A.M., Harris, W.S., O’Connell, T.D., and Wang, D. 2011. Omega-3 fatty acids prevent pressure overload-induced cardiac fibrosis through activation of cyclic GMP/protein kinase G signaling in cardiac fibroblasts. Circulation, 123(6):584-593. doi: 10.1161/circulationaha.110.971853.

Chetboul, V., Sampedrano, C.C., Gouni, V., Nicolle, A.P., Pouchelon, J.L., and Tissier, R. 2006. Ultrasonographic assessment of regional radial and longitudinal systolic function in healthy awake dogs. J. Vet. Intern. Med. 20(4):885-893. doi: 10.1111/j.19391676.2006.tb01802.x.

Craighead, J.J., Sumner, J.S., and Mitchell, J.A. 1995. The grizzly bears of Yellowstone: their ecology in the Yellowstone Ecosystem, 1959-1992. Island Press, Washington, D.C..

Crosson, E.R. 2008. WS-CRDS: Precision trace gas analysis and simplified stable isotope measurements. American Laboratory. November/December:37-41.

Dahle, B., Zedrossser, A., and Swenson, J.E. 2006. Correlates of body size and mass in yearling brown bears (Ursus arctos). J. Zool. (Lond.) 269(3):273-283. doi: 10.1111/j.14697998.2006.00127.x.

de Lorgeril, M., and Salen, P. 2012. New insights into the health effects of dietary saturated and omega-6 and omega-3 polyunsaturated fatty acids. BMC Med. 10:50. doi: 10.1186/17417015-10-50.

de Winter, J. C. F. 2013. Using the Student's t-test with extremely small sample sizes. Practical Assessment, Research \& Evaluation, 18(10):1-12. Available from: http://pareonline.net/getvn.asp? $v=18 \& n=10$ [accessed on May 22, 2015]. 
Erlenbach, J.A., Rode, K.D., Raubenheimer, D., and Robbins, C.T. 2014. Macronutrient optimization and energy maximization determine diets of brown bears. J. Mammal. 95(1):160-168. doi: 10.1644/13-mamm-a-161.

Esposito, K., Marfella, R., Ciotola, M., Di Palo, C., Giugliano, F., Giugliano, G., D’Armiento, M., D’Andrea, F., and Giugliano, D. 2004. Effect of a Mediterranean-style diet on endothelial dysfunction and markers of vascular inflammation in the metabolic syndrome: A randomized trial. J. Am. Med. Assoc. 292(12):1440-1446. doi: 10.1001/jama.292.12.1440.

Estruch, R., Ros, E., Salas-Salvadó, J., Covas, M., Corella, D., Arós, F., Gómez-Gracia, E., RuizGutiérrez, V., Fiol, M., Lapetra, J., Lamuela-Raventos, R.M., Serra-Majem, L., Pintó, X., Basora, J., Muñoz, M.A., Sorlí, J.V., Martínez, J.A., and Martínez-González, M.A. 2013. Primary prevention of cardiovascular disease with a Mediterranean diet. N. Engl. J. Med. 368(14):1279-1290. doi: 10.1056/NEJMoa1200303.

Farley, S.D., and Robbins, C.T. 1994. Development of two methods to estimate body composition of bears. Can. J. Zool. 72(2):220-226. doi: 10.1139/z94-029.

Felicetti, L.A., Robbins, C.T., and Shipley, L.A. 2003. Dietary protein content alters energy expenditure and composition of the mass gain in grizzly bears (Ursus arctos horribilis). Physiol. Biochem. Zool. 76(2):256-261. doi: 10.1086/374279.

Fernández-Real, J., Vendrell, J., and Ricart, W. 2005. Circulating adiponectin and plasma fatty acid profile. Clin. Chem. 51(3):603-609. doi: 10.1373/clinchem.2004.041350.

Folk, G.E. Jr., Hunt, J.M., and Folk, M.A. 1980. Further evidence for hibernation of bears. Bears: Their Biology and Management, 4:43-47. doi: 10.2307/3872841. 
Fontana, L., Eagon, J.C., Trujillo, M.E., Scherer, P.E., and Klein, S. 2007. Visceral fat adipokine secretion is associated with systemic inflammation in obese humans. Diabetes, 56(4):1010-1013. doi: 10.2337/db06-1656.

Fortin, J.K., Schwartz, C.C., Gunther, K.A., Teisberg, J.E., Haroldson, M.A., Evans, M.A., and Robbins, C.T. 2013. Dietary adjustability of grizzly bears and American black bears in Yellowstone National Park. J. Wildl. Manage. 77(2):270-281. doi: 10.1002/jwmg.483.

Frank, C.L., Karpovich, S., and Barnes, B.M. 2008. Dietary fatty acid composition and the hibernation patterns in free-ranging arctic ground squirrels. Physiol. Biochem. Zool. 81(4):486-495. doi: 10.1086/589107.

Fung, T.T., Rimm, E.B., Spiegelman, D., Rifai, N., Tofler, G.H., Willett, W.C., and Hu, F.B. 2001. Association between dietary patterns and plasma biomarkers of obesity and cardiovascular disease risk. Am. J. Clin. Nutr. 73(1):61-67.

Fung, T.T., Rexrode, K.M., Mantzoros, C., Manson, J.E., Willett, W.C., and Hu, F.B. 2009. Mediterranean diet and incidence of and mortality from coronary heart disease and stroke in women. Circulation, 119(8):1093-1100. doi: 10.1161/circulationaha.108.816736.

Gallagher, D., Heymsfield, S.B., Heo, M., Jebb, S.A., Murgatroyd, P.R., and Sakamoto, Y. 2000. Healthy percentage body fat ranges: an approach for developing guidelines based on body mass index. Am. J. Clin. Nutr. 72(3):694-701. Available from: http://ajcn.nutrition.org/content/72/3/694.short [accessed 11 April 2015].

Geiser, F., and Kenagy, G.J. 1987. Polyunsaturated lipid diet lengthens torpor and reduces body temperature in a hibernator. Am. J. Physiol. 252(5):897-901. 
Geiser, F., McAllan, B.M., and Kenagy, G.J. 1994. The degree of dietary fatty acid unsaturation affects torpor patterns and lipid composition of a hibernator. J. Comp. Physiol. B. 164(4):299-305. doi: 10.1007/bf00346446.

Grundy, S.M. 2004. Obesity, metabolic syndrome, and cardiovascular disease. J. Clin. Endocrinol. Metab. 89(6):2595-2600. doi: 10.1210/jc.2004-0372.

Guebre-Egziabher, F., Rabasa-Lhoret, R., Bonnet, F., Bastard, J-P., Desage, M., Skilton, M.R., Vidal, H, and Laville, M. 2008. Nutritional intervention to reduce the n-6/n-3 fatty acid ration increases adiponectin concentration and fatty acid oxidation in healthy subjects. Eur. J. Clin. Nutr. 62(11):1287-1293. doi: 10.1038/sj.ejen.1602857.

Harlow, H.J., and Frank, C.L. 2001. The role of dietary fatty acids in the evolution of spontaneous and facultative hibernation patterns in prairie dogs. J. Comp. Physiol. B. 171(1):77-84. doi: 10.1007/s003600000148.

Haskins, S.C. 1992. Inhalational anesthetics. Vet. Clin. North Am. Small Anim. Pract. 22(2):297-307. doi: 10.1016/s0195-5616(92)50614-3.

Heidemann, C., Schulze, M.B., Franco, O.H., van Dam, R.M., Mantzoros, C., and Hu, F.B. 2008. Dietary patterns and risk mortality from cardiovascular disease, cancer, and all-causes in a prospective cohort of women. Circulation, 118(3):230-237. doi: 10.1161/circulationaha.108.771881.

Hellgren, E.C. 1998. Physiology of hibernation in bears. Ursus, 10:467-477. Available from: http://www.jstor.org/stable/3873159 [accessed on 1 May 2013].

Jacoby, M.E., Hilderbrand, G.V., Servheen, C., Schwartz, C.C., Arthur, S.M., Hanley, T.A., Robbins, C.T., and Michener, R. 1999. Trophic relations of brown and black bears in 
several western North American ecosystems. J. Wildl. Manage. 63(3):921-929. doi: $10.2307 / 3802806$.

Jakobsen, M.U., O’Reilly, E.J., Heitmann, B.L., Pereira, M.A., Balter, K., Fraser, G.E., Goldbourt, U., Hallmans, G., Kenkt, P., Liu, S., Pietinen, P., Spiegelman, D., Stevens, J., Virtamo, J., Willett, W.C., and Ascherio, A. 2009. Major types of dietary fat and risk of coronary heart disease: a pooled analysis of 11 cohort studies. Am. J. Clin. Nutr. 89:1425-32. doi: 10.3945/ajen.2008.27124.

Kennedy, A., Martinez, K., Chuang, C., LaPoint, K., and McIntosh, M. 2009. Saturated fatty acid-mediated inflammation and insulin resistance in adipose tissue: Mechanisms of action and implications. J. Nutr. 139(1):1-4. doi: 10.3945/jn.108.098269.

Kovach, A.I., and Powell, R.A. 2003. Effects of body size on male mating tactics and paternity in black bears, Ursus americanus. Can. J. Zool. 81(7):1257-1268. doi: 10.1139/z03-111.

Kuecherer, H., Abbott, J.A., Botvinick, E.H., O’Connell, J.W., Dae, M.W., Scheinman, E.D., Scheinman, M.D., and Schiller, N.B. 1991. Echo phase analysis as an adjunct to endocardial mapping in the WPA syndrome. J. Am. Coll. Cardiol. 17(2):A50. doi: 10.1016/0735-1097(91)91167-d.

Kusunoki, M., Tsutsumi, K., Nakayama, M., Kurokawa, T., Nakamura, T., Ogawa, H., Fukuzawa, Y., Morishita, M., Koide, T., and Miyata, T. 2007. Relationship between serum concentration of saturated fatty acids and unsaturated fatty acids and the homeostasis model insulin resistance index in Japanese patients with type 2 diabetes mellitus. J. Med. Invest. 54(3,4):243-247. doi: 10.2152/jmi.54.243. 
Lang, C.H., Frost, R.A., Nairn, A.C., McLean, D.A., and Vary, T.C. 2002. TNF- $\alpha$ impairs heart and skeletal muscle protein synthesis by altering translation initiation. Am. J. Physiol. Endocrinol. Metab. 282(2):E336-E347. doi: 10.1152/ajpendo.00366.2001.

LeBlanc, P.J., Obbard, M., Battersby, B.J., Felskie, A.K., Brown, L., Wright, P.A., and Ballantyne, J.S. 2001. Correlations of plasma lipid metabolites with hibernation and lactation in wild black bears Ursus americanus. J. Comp. Physiol. B. 171(4):327-334. doi: $10.1007 / \mathrm{s} 003600100180$.

Lenchik, L., Register, T.C., Hsu, F-C., Lohman, K., Nicklas, B.J., Freedman, B.I., Langefeld, C.D., Carr, J.J., and Bowden, D.W. 2003. Adiponectin as a novel determinant of bone mineral density and visceral fat. Bone, 33(4):646-651. doi: 10.1016/s87563282(03)00237-0.

Libby, P., Okamoto, Y., Rocha, V.Z., and Folco, E. 2010. Inflammation in atherosclerosis: Transition from theory to practice. Circ. J. 74(2):213-220. doi: 10.1253/circj.cj-09-0706.

Lopez-Alfaro, C., Robbins, C.T., Zedrosser, A., and Nielsen, S.E. 2013. Energetics of hibernation and reproductive trade-offs in brown bears. Ecol. Model. 270:1-10. doi: 10.1016/j.ecolmodel.2013.09.002.

Lusby, A.L., Kania, S.A., Abd-Eldaim, M., Bartges, J.W., and Kirk, C.A. 2008. Detection of serum adiponectin in the cat, bear, and horse using antibody from a commercial ELISA kit. J. Anim. Physiol. Anim. Nutr. 92(2):220-221.

Mann, D.L., and Young, J.B. 1994. Basic mechanisms in congestive heart failure: Recognizing the role of proinflammatory cytokines. CHEST, 105(3):897-904. Available from http://dx.doi.org/10.1378/chest.105.3.897 [accessed 18 March 2015]. 
Marfella, R., Esposito, K., Siniscalchi, M., Cacciapuoti, F., Giugliano, F., Labriola, D., Ciotola, M., Di Palo, C., Misso, L, and Giugliano, D. 2004. Effect of weight loss on cardiac synchronization and proinflammatory cytokines in premenopausal obese women. Diabetes Care, 27(1):47-52. doi: 10.2337/diacare.27.1.47.

Mauviel, A., Heino, J., Kähäri, V., Hartmann, D-J., Loyau, G., Pujol, J-P., and Vuorio, E. 1991. Comparative effects of interleukin-1 and tumor necrosis factor- $\alpha$ on collagen production and corresponding procollagen mRNA levels in human dermal fibroblasts. J. Invest. Dermatol. 96(2):243-249. doi: 10.1111/1523-1747.ep12462185.

McLeish, I. 1977. Doppler ultrasonic arterial pressure measurement in the cat. Vet. Rec. 100(14):290-291. doi: 10.1136/vr.100.14.290.

McLellan, B.N. 2011. Implications of a high-energy and low-protein diet on the body composition, fitness, and competitive abilities of black (Ursus americanus) and grizzly bears (Ursus arctos). Can. J. Zool. 89(6):546-558. doi: 10.1139/z11-026.

Metabolic Solutions Inc. 2014. Total body water measurements [online]. Available from: https://www.metsol.com/assets/sites/3/Total-Body-Water-Determination.pdf [ accessed 15 May 2015].

Millen, A.M.E., Libhaber, C.D., Majane, O.H.I., Libhaber, E., Maseko, M.J., Woodiwiss, A.J., and Norton, G.R. 2014. Relative impact of blood pressure as compared to an excess adiposity on a left ventricular diastolic dysfunction in a community sample with a high prevalence of obesity. J. Hypertens. 32(12):2457-2464. doi:

10.1097/hjh.0000000000000330.

Murakami, K., Sasaki, S., Uenishi, K., and the Japan Dietetic Students' Study for Nutrition and Biomarkers Group. 2013. Serum adiponectin concentration in relation to macronutrient 
and food intake in young Japanese women. Nutrition, 29(11-12):1315-1320. doi: 10.1016/j.nut.2013.04.012.

Nelson, R.A. 1973. Winter sleep in the black bear: a physiologic and metabolic marvel. Mayo Clin. Proc. 48(10):733-737. Available from: http://www.ncbi.nlm.nih.gov/pubmed/4745546 [accessed 15 May 2015].

Nelson, O.L., and Robbins, C.T. 2010. Cardiac function adaptations in hibernating grizzly bears (Ursus arctos horribilis). J. Comp. Physiol. B. 180(3):465-473. doi: 10.1007/s00360009-0421-X.

Ommen, S.R., Nishimura, R.A., Appleton, C.P., Miller, F.A., Oh, J.K., Redfield, M.M., and Tajik, A.J. 2000. Clinical utility of Doppler echocardiography and tissue Doppler imaging in the estimation of left ventricular filling pressures: A comparative simultaneous Doppler-catheterization study. Circulation, 102(15):1788-1794. doi: 10.1161/01.cir.102.15.1788.

Oral, H., Kapadia, S., Nakano, M., Torre-Amjone, G., Lee, J., Lee-Jackson, D., Young, J.B., and Mann, D.L. 1995. Tumor necrosis factor- $\alpha$ and the failing human heart. Clin. Cardiol. 18(9 Suppl IV):20-27. doi: 10.1002/clc.4960181605.

Orhan, A.L., Uslu, N., Dayi, S.U., Nurkalem, Z., Uzun, F., Erer, H.B., Hasdemir, H., Emre, A., Karakus, G., Soran, O., Gorcsan, J., and Eren, M. 2010. Effects of isolated obesity on left and right ventricular function: a tissue Doppler and strain imaging study. Echocardiography, 27(3):236-243. doi: 10.1111/j.1540-8175.2009.01024.x.

Pagani, F.D., Baker, L.S., His, C., Knox, M., Fink, M.P., and Visner, M.S. 1992. Left ventricular systolic and diastolic dysfunction after infusion of tumor necrosis factor- $\alpha$ in conscious dogs. J. Clin. Invest. 90(2):389-398. doi: 10.1172/jci115873. 
Pescatello, L.S., and the American College of Sports Medicine. 2014. ACSM's guidelines for exercise testing and prescription. Wolters Kluwer/Lippincott Williams \& Wilkins Health, Philadelphia.

Phillips, C.M., Kesse-Guyot, E., McManus, R., Hercberg, S., Lairon, D., Planells, R., and Roche, H.M. 2012. High dietary saturated fat intake accentuates obesity risk associated with the fat mass and obesity-associated gene in adults. J. Nutr. 142(5):824-31. doi: 10.3945/jn.111.153460.

Pritchard, G.T., and Robbins, C.T. 1990. Digestive and metabolic efficiencies of grizzly and black bears. Can. J. Zool. 68(8):1645-1651. doi: 10.1139/z90-244.

Quinn, L.S., and Anderson, B.G. 2011. Interleukin-15, IL-15 receptor-alpha, and obesity: Concordance of laboratory animal and human genetic studies. J. Obes. 2011:1-8. doi: $10.1155 / 2011 / 456347$

Rajagopalan, N., Garcia, M.J., Rodriguez, L., Murray, R.D., Apperson-Hansen, C., Stugaard, M., Thomas, J.D., and Klein, A.L. 2001. Comparison of new Doppler echocardiographic methods to differentiate constrictive pericardial heart disease and restrictive cardiomyopathy. Am. J. Cardiol. 87(1):86-94. doi: 10.1016/s0002-9149(00)01278-9.

Reis, C.E.G., Bressan, J., and Alfenas, R.C.G. 2010. Effect of the diet components on adiponectin levels. Nutr. Hosp. 25(6):881-888. doi: 0.3305/nh.2010.25.6.4760.

Rigano, K.S., Gehring, J.L., Evans Hutzenbiler, B.D., Chen, A.V., Nelson, O.L., Vella, C.A., Robbins, C.T., and Jansen, H.T. 2016. Life in the fat lane: seasonal regulation of insulin sensitivity, food intake, and adipose biology in brown bears. J. Comp. Physiol. B. 187(4):649-676. doi:10.1007/s00360-016-1050-9. 
Roberts, A.W., Clark, A.L., and Witte, K.K. 2009. Left ventricular dysfunction and heart failure in metabolic syndrome and diabetes without overt coronary artery disease - do we need to screen our patients? Diabetes Vasc. Dis. Res. 6(3):153-163. doi: $10.1177 / 1479164109338774$.

Robbins, C.T., Ben-David, M., Fortin, J.K., and Nelson, O.L. 2012. Maternal condition determines birth date and growth of newborn bear cubs. J. Mammal. 93(2):540-546. doi: 10.1644/11-mamm-a-155.1.

Rogers, L.L. 1981. A bear in its lair. Natural History [online]. 90(10):64-70. Available from: http://bearstudy.org/website/images/stories/Publications/A_Bear_in_its_Lair.pdf [accessed 11 April 2013].

Ruxton, C. 2004. Health benefits of omega-3 fatty acids. Nurs. Stand. 18(48):38-42. doi: 10.7748/ns2004.08.18.48.38.c3668.

Saidijam, M., Tootoonchi, A.S., Goodarzi, M.T., Hassanzadeh, T., Borzuei, S.H., Yadegarazari, R., and Shabab, N. 2014. Expression of interleukins $7 \& 8$ in peripheral blood mononuclear cells from patients with metabolic syndrome: A preliminary study [online]. Indian J. Med. Res. 140:238-243. Available from: http://www.ijmr.org.in [accessed 8 April 2016].

Sanchez, A.A., Levy, P.T., Sekarski, T.J., Arbelaez, A.M., Hildebolt, C.F., Holland, M.R., and Singh, G.K. 2014. Markers of cardiovascular risk, insulin resistance, and ventricular dysfunction and remodeling in obese adolescents. J. Pediatr. 166(3):660-665. doi: 10.1016/j.jpeds.2014.11.012. 
Santos, S., Oliveira, A., Casal, S., and Lopes, C. 2013. Saturated fatty acids intake in relation to C-reactive protein, adiponectin, and leptin: A population-based study. Nutrition, 29(6):892-897. doi: 10.1016/j.nut.2013.01.009.

Schiller, N.B., Shah, P.M., Crawford, M., DeMaria, A., Devereux, R., Feigenbaum, H., Gutgesell, H., Reicheck, N., Sahn, D., and Schnittger, I. 1989. Recommendations for quantitation of the left ventricle by two-dimensional echocardiography. American Society of Echocardiography Committee on Standards, Subcommittee on Quantitation of TwoDimensional Echocardiograms. J. Am. Soc. Echocardiogr. 2(5):358-367. doi: 10.1016/s0894-7317(89)80014-8.

Sikes, R.S., Gannon, W.L., and the Animal Care and Use Committee of the American Society of Mammalogists. 2011. Guidelines of the American Society of Mammalogists for the use of wild mammals in research. J. Mammal. 92(1):235-253. doi: 10.1644/10-mamm-f355.1 .

Siri-Tarino, P.W., Sun, Q., Hu, F.B., and Krauss, R.M. 2010. Meta analysis of prospective cohort studies evaluating the association of saturated fat with cardiovascular disease. Am. J. Clin. Nutr. 91:535-546. doi: 10.3945/ajen.2009.27725.

Stenvinkel, P., Jani, A., and Johnson, R. 2013. Hibernating bears (Ursidae): metabolic magicians of definite interest for the nephrologist. Kidney Int. 83(2):207-212. doi: 10.1038/ki.2012.396.

Sun, X., Pan, H., Tan, H., and Yu, Y. 2012. High free fatty acids level related with cardiac dysfunction in obese rats. Diabetes Res. Clin. Pract. 95(2):251-259. doi: 10.1016/j.diabres.2011.10.028. 
Teisberg, J.E., Farley, S.D., Nelson, O.L., Hilderbrand, G.V., Madel, M.J., Owen, P.A., Erlenbach, J.A., and Robbins, C.T. 2014. Immobilization of grizzly bears (Ursus arctos) with dexmedetomidine, tiletamine, and zolazepam. J. Wildl. Dis. 50(1):74-83. doi: $10.7589 / 2012-11-273$.

Thomas, W.P., Gaber, C.E., Jacobs, G.J., Kaplan, P.M., Lombard, C.W., Moise, N.S., and Moses, B.L. 1993. Recommendations for standards in transthoracic two-dimensional echocardiography in the dog and cat. J. Vet. Intern. Med. 7(4):247-252. doi: 10.1111/j.1939-1676.1993.tb01015.x.

Thorsen, T., Shriver, T., Racine, N., Richman, B., and Schoeller, D.A. 2011. Doubly labeled water analysis using cavity ring-down spectroscopy. Rapid Commun. Mass Spectrom. 25(1):3-8. doi: 10.1002/rcm.4795.

Tidholm, A., Ljungvall, I., Höglund, K., Westling, A.B., and Häggström, J. 2009. Tissue Doppler and strain imaging in dogs with myxomatous mitral valve disease in different stages of congestive heart failure. J. Vet. Intern. Med. 23(6):1197-1207. doi: 10.1111/j.1939-1676.2009.0403.x.

Tur, J.A., Bibiloni, M.M., Sureda, A., and Pons, A. 2012. Dietary sources of omega 3 fatty acids: public health risks and benefits. Br. J. Nutr. 107(S2):S23-S52. doi: $10.1017 / \mathrm{s} 0007114512001456$.

U.S. Department of Agriculture, U.S. Department of Health and Human Services. 2010. Dietary Guidelines for Americans. $7^{\text {th }}$ ed. U.S. Government Printing Office, Washington, D.C.. Vaccaro, J.A., and Huffman, F.G. 2011. Monounsaturated fatty acid, carbohydrate intake, and diabetes status are associated with arterial pulse pressure. Nutr. J. 10(1):126-133. doi: 10.1186/1475-2891-10-126. 
Viscarra, J.A., and Ortiz, R.M. 2013. Cellular mechanisms regulating fuel metabolism in mammals: Role of adipose tissue and lipids during prolonged food deprivation. Metab., Clin. Exp. 62(7):889-897. doi: 10.1016/j.metabol.2012.12.014.

Ware, J.V., Nelson, O.L., Robbins, C.T., and Jansen, H.T. 2012. Temporal organization of activity in the brown bear (Ursus arctos): roles in circadian rhythms, light, and food entrainment. Am. J. Physiol. Regul. Integr. Comp. Physiol. 303(9):R890-R902. doi: 10.1152/ajpregu.00313.2012.

Welch, C.A., Keay, J., Kendall, K.C., and Robbins, C.T. 1997. Constraints on frugivory by bears. Ecology, 78(4):1105-1119. doi: 10.2307/2265862.

You, M., Considine, R.V., Leone, T.C., Kelly, D.P., and Crabb, D.W. 2005. Role of adiponectin in the protective action of dietary saturated fat against alcoholic fatty liver in mice. Pathobiology, 42(3):568-577. doi: 10.1002/hep.20821. 
Figure Captions

Fig. 1 The mean amount of food (fresh weight basis) consumed per day during the active season (May-October) by grizzly bears (Ursus arctos horribilis) involved in the dietary study and their corresponding body masses.

Fig. 2 Mean serum concentrations of inflammatory markers analyzed from grizzly bears (Ursus arctos horribilis) eating both the PUFA diet and the SFA diet; a P value of $<0.05$ was considered significant.

Fig. 3 Representative transverse velocities of left ventricular wall motion indicating the direction of myocardial movement and the velocity or vigor of the myocardial movement taken at the same point in early diastole $(\mathrm{cm} / \mathrm{s})$ in grizzly bears (Ursus arctos horribilis) on the 2 different diets $(1 \mathrm{a}=$ PUFA and $1 \mathrm{~b}=$ SFA $)$.

Fig. 4 Activity counts recorded per day during active season (March - October), the deepest part of hibernation (December 15 - January 15), and total hibernation duration (November February) compared by diet type (PUFA vs. SFA). Active season mean counts are $317,271 \pm 77,413$ for PUFA and 204,774 \pm 78,529 for SFA. Deep hibernation mean counts are 5,570 $\pm 1,253$ for PUFA and 11,381 \pm 4,240 for SFA, while all hibernation mean counts are $25,587 \pm 9,860$ for PUFA and 40,011 $\pm 19,693$ for SFA. All means are presented \pm SEM. 
Figure 1.

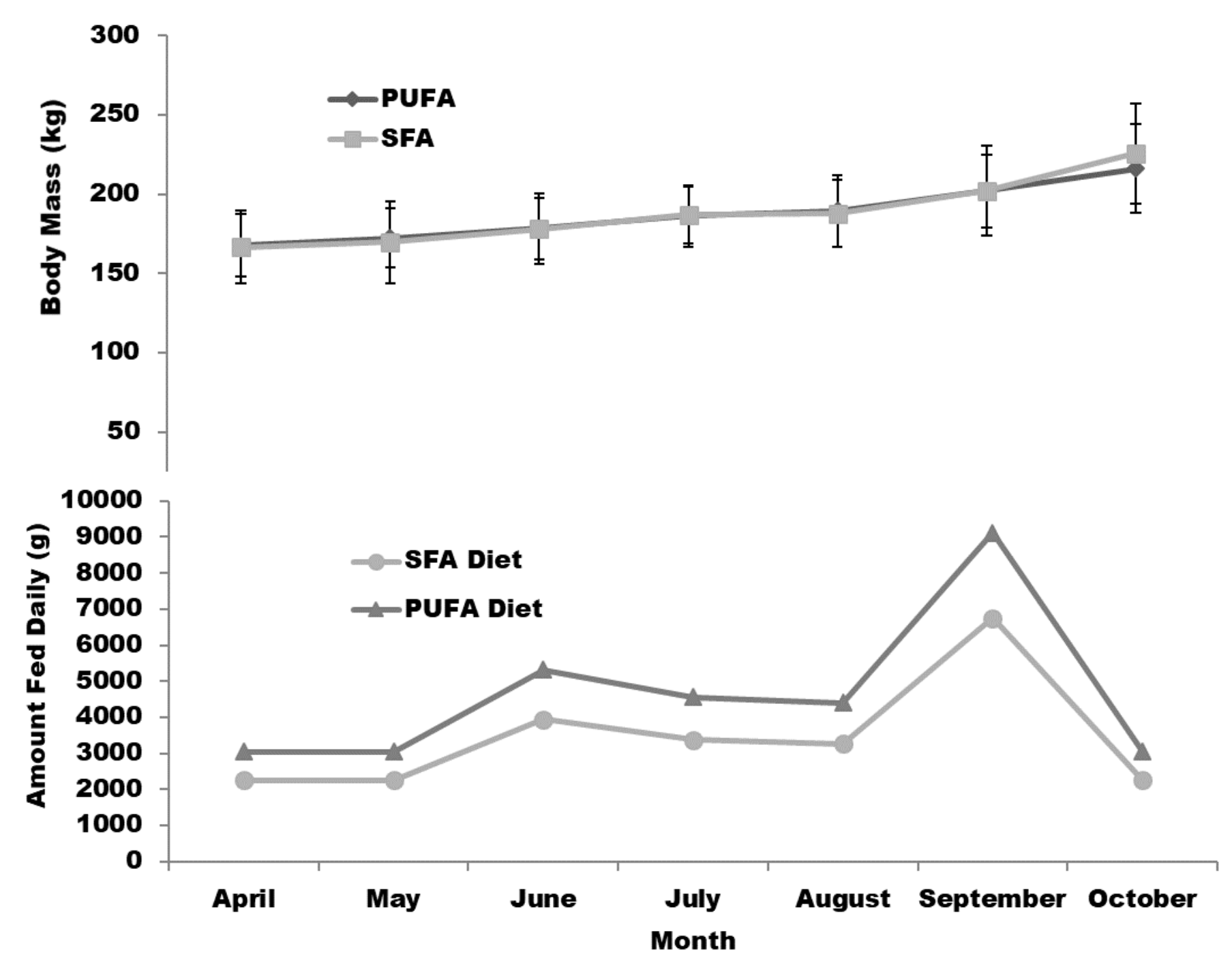

https://mc06.manuscriptcentral.com/cjz-pubs 
Figure 2

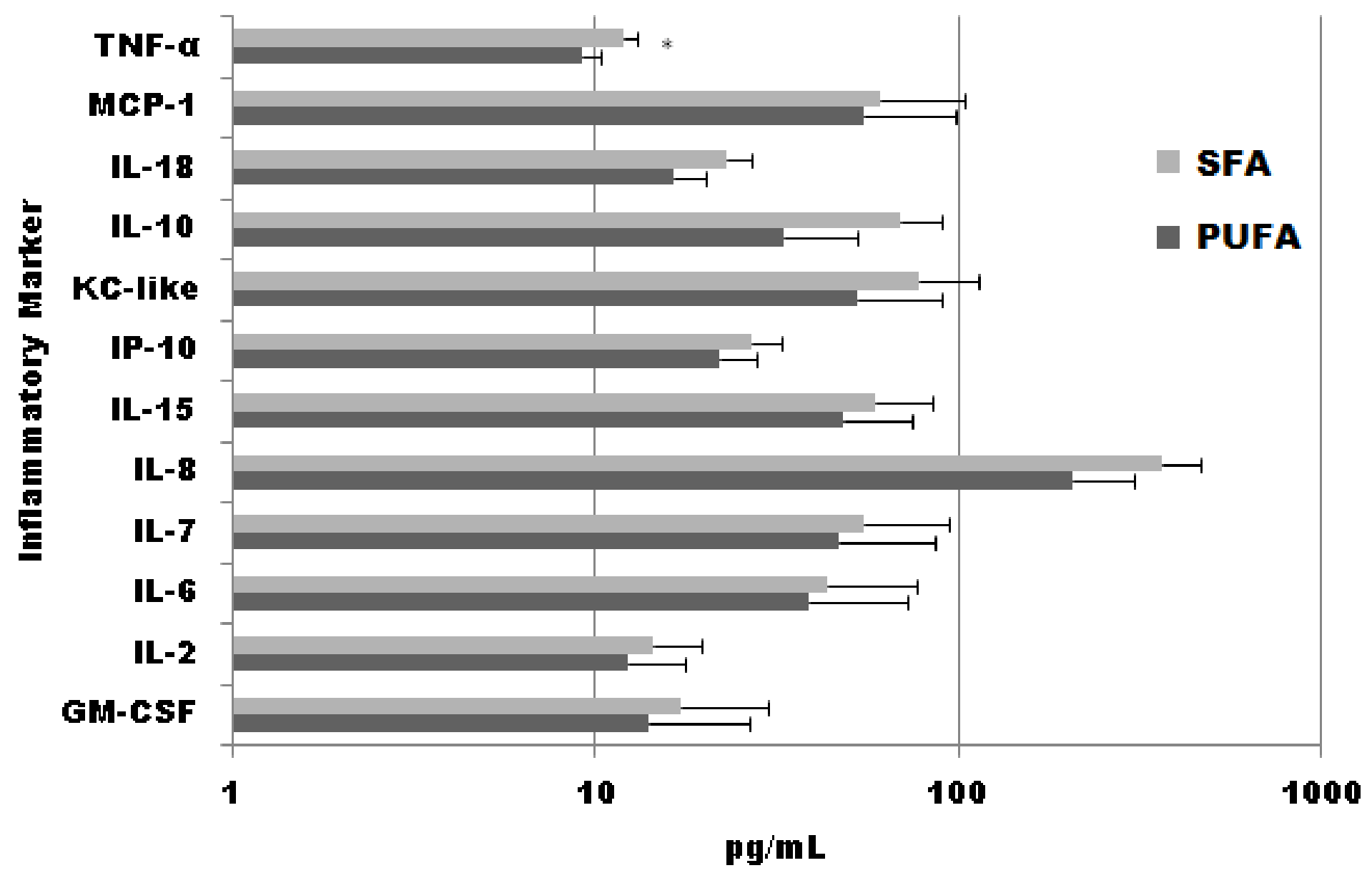


Figure 3.
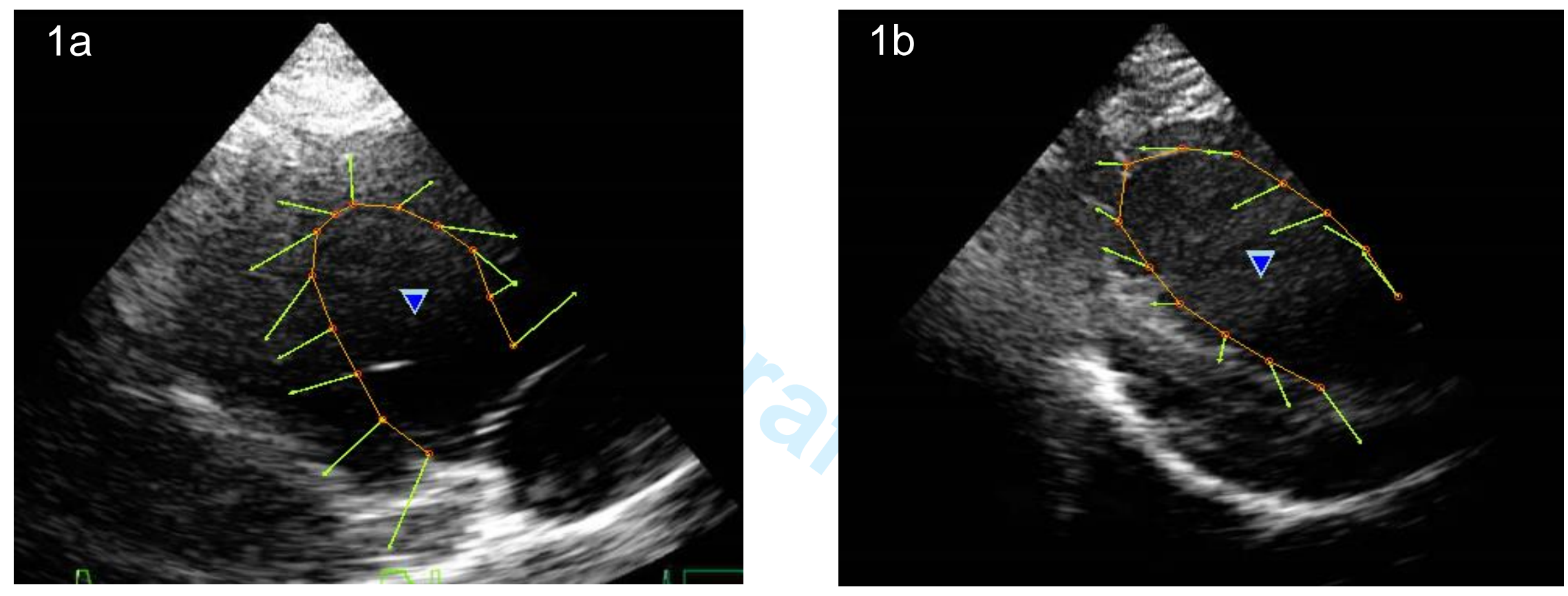
Figure 4.
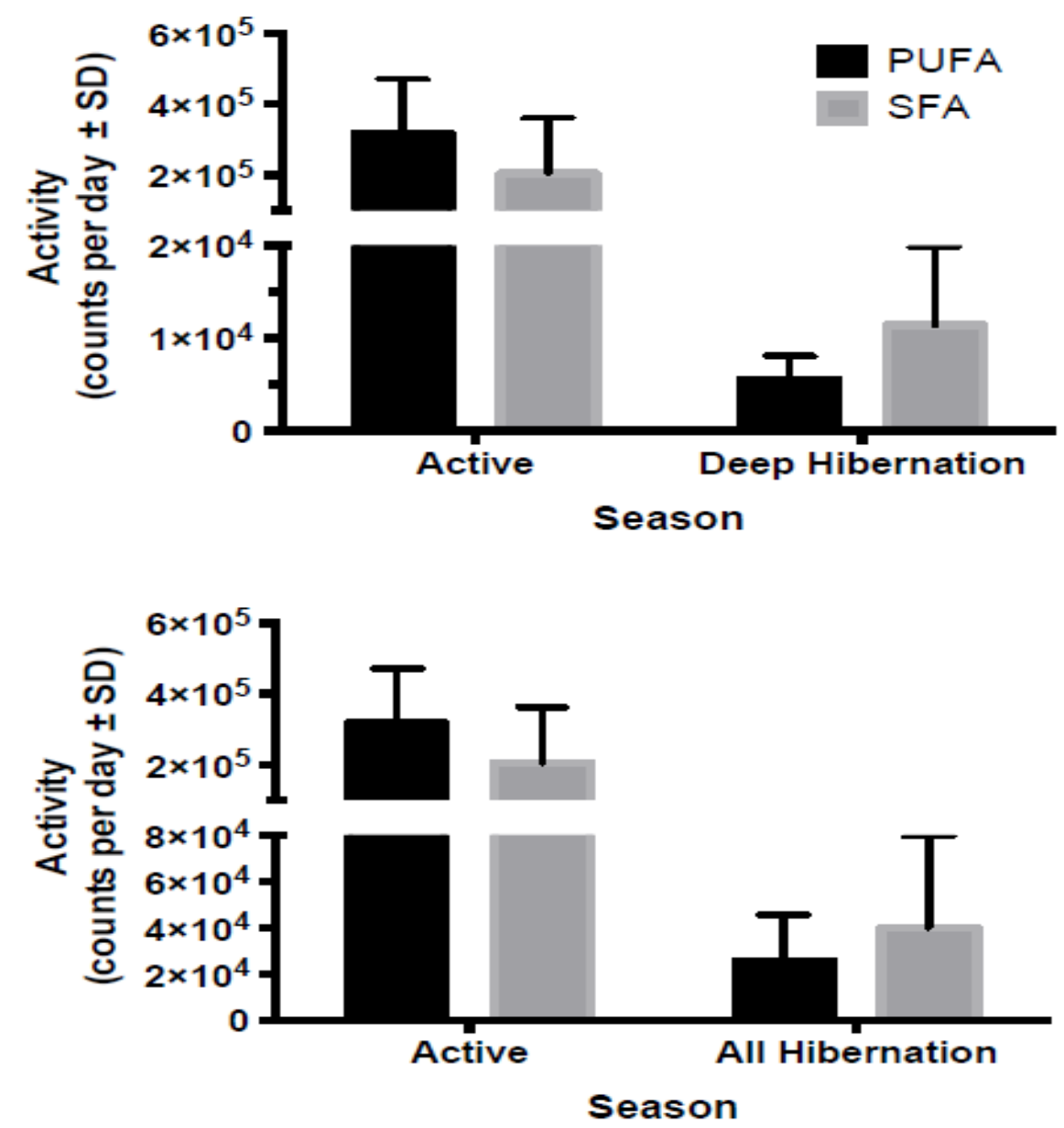
Table 1. Proportions of the ingredients and compositions of the two diets (PUFA and SFA) used to test the physiological responses of grizzly bears (Ursus arctos horribilis) to dietary fats with dietary proportions and compositions expressed on a $100 \%$ dry matter basis.

\begin{tabular}{lll}
\hline Item & PUFA Diet & SFA Diet \\
\hline & & \\
Ingredient & 17.5 & 22.9 \\
Apples & 30.6 & 40.3 \\
Commercial Chow ${ }^{a}$ & - & 10.1 \\
Beef Tallow & - & 14.1 \\
Cheddar Cheese & - & 3.9 \\
Ground Beef & - & 8.7 \\
High Fructose Corn Syrup & 11.0 & - \\
Oats & 37.0 & - \\
Salmon & 3.9 & - \\
Salmon Oil & & \\
& 5.30 & \\
Dietary Composition & 38.5 & 5.18 \\
Gross Energy (kcal/g dry matter) & 17.0 & 17.5 \\
Crude Protein (\% dry matter) & 39.2 & 25.5 \\
Total Fat (\% dry matter) & 29.8 & 18.2 \\
Calories from Protein (\% of total calories) & 45.8 \\
Calories from Fat (\% of total calories) & & 28.8 \\
Calories from SFA (\% of total calories) ${ }^{b}$ & 9.5 & \\
\hline
\end{tabular}

${ }^{a}$ Science Diet Canine Adult, Hill's Pet Nutrition, Topeka, KS

${ }^{b}$ Available calories in each diet estimated from feeding and digestive studies of Pritchard and

Robbins (1990) and Erlenbach et al. (2014) 
Table 2. Fatty acid composition (\% of total fatty acids) of the diet on a $100 \%$ dry matter basis and the resulting serum fatty acid and lipid profiles ( $\mu \mathrm{mol} / \mathrm{L}$ for fatty acids, $\mathrm{mg} / \mathrm{dL}$ for serum lipids, and $\mathrm{ng} / \mathrm{mL}$ for insulin).

\begin{tabular}{|c|c|c|c|c|c|c|}
\hline & Fatty Acid/Lipid Profile & $\begin{array}{l}\text { PUFA } \\
\text { Diet } \\
\end{array}$ & $\begin{array}{l}\text { PUFA } \\
\text { Serum } \\
\end{array}$ & $\begin{array}{l}\text { SFA } \\
\text { Diet }\end{array}$ & $\begin{array}{l}\text { SFA } \\
\text { Serum } \\
\end{array}$ & $P$-Value \\
\hline \multirow[t]{4}{*}{ PUFA Omega 3} & Eicosapentaenoic & 3.66 & $806.8 \pm 229.0$ & 0.01 & $85.3 \pm 40.5$ & 0.001 \\
\hline & Docosapentaenoic & 1.64 & $170.8 \pm 29.0$ & 0.01 & $63.8 \pm 39.7$ & 0.005 \\
\hline & Docosahexaenoic & 6.09 & $480.3 \pm 93.4$ & 0.02 & $102.5 \pm 21.7$ & $<0.001$ \\
\hline & TOTAL OMEGA 3 & 11.39 & $1511.6 \pm 324.2$ & 0.04 & $299.5 \pm 120.8$ & 0.003 \\
\hline \multirow[t]{5}{*}{ PUFA Omega 6} & Linoleic & 9.18 & $1378.8 \pm 361.5$ & 6.75 & $1884 \pm 453.1$ & 0.132 \\
\hline & Arachidonic & 4.67 & $545 \pm 102.7$ & 0.15 & $626.8 \pm 107.3$ & 0.313 \\
\hline & Gamma Linoleic & - & $11.5 \pm 3$ & - & $31.8 \pm 7.1$ & 0.009 \\
\hline & Dihomogamma Linolenic & - & $75.3 \pm 18.4$ & - & $124.8 \pm 11.4$ & 0.017 \\
\hline & TOTAL OMEGA 6 & 13.85 & $2058.8 \pm 445.6$ & 6.90 & $2766.8 \pm 1539.1$ & 0.847 \\
\hline \multirow[t]{2}{*}{ PUFA Omega 9} & Docosatetraenoic & - & $14.1 \pm 2.2$ & - & $32.3 \pm 10.2$ & 0.028 \\
\hline & Mead & - & $10.1 \pm 1.3$ & - & $95.4 \pm 36$ & 0.019 \\
\hline \multirow[t]{7}{*}{ Monounsaturated } & Myristoleic & 0.94 & $3.1 \pm 1.8$ & 0.89 & $29.1 \pm 21.9$ & 0.056 \\
\hline & Palmitoleic & 5.67 & $113.5 \pm 72.4$ & 2.52 & $99.8 \pm 49.2$ & 0.764 \\
\hline & Vaccenic & 0.49 & $198.2 \pm 57.4$ & 0.11 & $142 \pm 21.6$ & 0.175 \\
\hline & Oleic & 27.09 & $1178.8 \pm 350.3$ & 29.92 & $1614 \pm 523.7$ & 0.216 \\
\hline & 11-Eicosenoic & 3.81 & $64.5 \pm 27.1$ & 0.29 & $15.9 \pm 4.2$ & 0.012 \\
\hline & Nervonic & 0.6 & $11.5 \pm 6.0$ & 0.03 & $1.6 \pm 0.3$ & 0.020 \\
\hline & TOTAL MUFA & 38.6 & $1569.5 \pm 497.7$ & 33.80 & $1902.4 \pm 576.0$ & 0.614 \\
\hline \multirow[t]{7}{*}{ Saturated } & Myristic & 3.63 & $71.3 \pm 55.3$ & 9.35 & $142 \pm 80.8$ & 0.020 \\
\hline & Palmitic & 16.69 & $1122.3 \pm 321.7$ & 24.46 & $1718 \pm 665.8$ & 0.158 \\
\hline & Stearic & 5.63 & $1663.8 \pm 319.8$ & 16.87 & $1688.6 \pm 238.3$ & 0.905 \\
\hline & Lignoceric & 0.05 & $3.7 \pm 1.3$ & 0.03 & $2.4 \pm 0.5$ & 0.126 \\
\hline & Pentadecanoic & 0.16 & $19.6 \pm 10.7$ & 1.17 & $32.1 \pm 18.4$ & 0.282 \\
\hline & Heptadecanoic & 0.26 & $71.7 \pm 21.7$ & 1.05 & $99.4 \pm 28.7$ & 0.175 \\
\hline & TOTAL SFA & 26.42 & $3075.4 \pm 711.4$ & 52.93 & $3792.6 \pm 1089.4$ & 0.462 \\
\hline \multirow[t]{5}{*}{ Lipid Panel } & Cholesterol & - & $230.3 \pm 48.8$ & - & $224.3 \pm 37.6$ & 0.850 \\
\hline & Triglyceride & - & $282.8 \pm 30.8$ & - & $230.3 \pm 59.1$ & 0.170 \\
\hline & BUN & - & $21.5 \pm 6.0$ & - & $16.8 \pm 4.3$ & 0.250 \\
\hline & HDL & - & $107.5 \pm 13.3$ & - & $130.3 \pm 28.0$ & 0.190 \\
\hline & LDL & - & $11 \pm 7.4$ & - & $11.3 \pm 5.3$ & 0.960 \\
\hline
\end{tabular}




\begin{tabular}{llllll}
\hline NEFA & - & $0.2 \pm<0.1$ & - & $0.3 \pm 0.1$ & 0.170 \\
Insulin & - & $0.10 \pm 0.01$ & - & $0.09 \pm 0.03$ & 0.245 \\
\hline
\end{tabular}


Table 3. Echocardiographic regional strain imaging and blood pressure variables (mean \pm standard deviation) recorded in

unanesthetized grizzly bears (Ursus arctos horribilis) eating PUFA and SFA diets in the fall after one season of diet consumption and at the fattest body composition.

\begin{tabular}{llll}
\hline Variable & PUFA & SFA & P-Value \\
\hline Strain & & & \\
Longitudinal velocity of LV wall in systole $(\mathrm{cm} / \mathrm{s})$ & $9.0 \pm 2.5$ & $3.8 \pm 0.6$ & 0.023 \\
Longitudinal velocity of LV wall in early diastole $(\mathrm{cm} / \mathrm{s})$ & $-5.4 \pm 2.1$ & $-3.0 \pm 1.6$ & 0.270 \\
Longitudinal velocity of LV wall during atrial contraction $(\mathrm{cm} / \mathrm{s})$ & $-6.7 \pm 2.9$ & $-3.6 \pm 0.6$ & 0.075 \\
Transverse velocity of LV wall in systole $(\mathrm{cm} / \mathrm{s})$ & $6.6 \pm 0.8$ & $5.7 \pm 1.1$ & 0.386 \\
Transverse velocity of LV wall in early diastole $(\mathrm{cm} / \mathrm{s})$ & $-7.6 \pm 0.7$ & $-4.3 \pm 2.0$ & 0.018 \\
Transverse velocity of LV wall during atrial contraction $(\mathrm{cm} / \mathrm{s})$ & $-2.9 \pm 1.8$ & $-7.0 \pm 0.8$ & 0.016 \\
Strain, percent change of LV wall during systole & $-21 \pm 4.2$ & $-23.5 \pm 4.2$ & 0.426 \\
Strain, percent change of LV wall during diastole & $0.5 \pm 0.4$ & $2.5 \pm 1.0$ & 0.426 \\
Strain rate during systole (1/s) & $-1.8 \pm 0.5$ & $-1.8 \pm 0.3$ & 0.055 \\
Strain rate during early diastole $(1 / \mathrm{s})$ & $1.1 \pm 0.7$ & $1.2 \pm 0.5$ & 0.934 \\
Strain rate during atrial contraction $(1 / \mathrm{s})$ & $0.8 \pm 0.2$ & $1.3 \pm 1.3$ & 0.838 \\
Maximum filling volume of heart $(\mathrm{mL})$ & $282.5 \pm 49.6$ & $340 \pm 28.1$ & 0.090 \\
Percent left ventricular ejection fraction $(\%)$ & $62.5 \pm 3.4$ & $53.3 \pm 3.9$ & 0.051 \\
Stroke volume (mL) & $156.8 \pm 9.3$ & $180.5 \pm 21.8$ & 0.192 \\
Systolic blood pressure (mmHg) & $228.4 \pm 10.3$ & $236.3 \pm 8.7$ & 0.172 \\
Diastolic blood pressure (mmHg) & $122.5 \pm 2.2$ & $152.6 \pm 9.9$ & 0.006 \\
Heart rate, beats per min & $81 \pm 9.3$ & $82.8 \pm 9.7$ & 0.803 \\
\hline
\end{tabular}

